\title{
An antiproliferative BMP-2/PPAR $/$ apoE axis in human and murine SMCs and its role in pulmonary hypertension
}

\author{
Georg Hansmann, ${ }^{1,2}$ Vinicio A. de Jesus Perez,, Tero-Pekka Alastalo, ${ }^{1}$ \\ Cristina M. Alvira, ${ }^{1}$ Christophe Guignabert, ${ }^{1}$ Janine M. Bekker, ${ }^{1}$ Stefan Schellong, ${ }^{1}$ \\ Takashi Urashima, ${ }^{1}$ Lingli Wang, ${ }^{1}$ Nicholas W. Morrell, ${ }^{3}$ and Marlene Rabinovitch ${ }^{1}$ \\ ${ }^{1}$ Department of Pediatrics, Stanford University School of Medicine, Stanford, California, USA. '2Department of Pediatrics, UCSF, \\ San Francisco, California, USA. ${ }^{3}$ Department of Medicine, University of Cambridge, Cambridge, United Kingdom.
}

\begin{abstract}
Loss-of-function mutations in bone morphogenetic protein receptor II (BMP-RII) are linked to pulmonary arterial hypertension (PAH); the ligand for BMP-RII, BMP-2, is a negative regulator of SMC growth. Here, we report an interplay between PPAR $\gamma$ and its transcriptional target apoE downstream of BMP-2 signaling. BMP-2/BMP-RII signaling prevented PDGF-BB-induced proliferation of human and murine pulmonary artery SMCs (PASMCs) by decreasing nuclear phospho-ERK and inducing DNA binding of PPAR $\gamma$ that is independent of Smad1/5/8 phosphorylation. Both BMP-2 and a PPAR $\gamma$ agonist stimulated production and secretion of apoE by SMCs. Using a variety of methods, including short hairpin RNAi in human PASMCs, PAH patient-derived BMP-RII mutant PASMCs, a PPAR $\gamma$ antagonist, and PASMCs isolated from PPAR $\gamma$-and apoE-deficient mice, we demonstrated that the antiproliferative effect of BMP-2 was BMP-RII, PPAR $\gamma$, and apoE dependent. Furthermore, we created mice with targeted deletion of PPAR $\gamma$ in SMCs and showed that they spontaneously developed PAH, as indicated by elevated RV systolic pressure, RV hypertrophy, and increased muscularization of the distal pulmonary arteries. Thus, PPAR $\gamma$-mediated events could protect against PAH, and PPAR $\gamma$ agonists may reverse PAH in patients with or without BMP-RII dysfunction.
\end{abstract}

\section{Introduction}

Bone morphogenetic protein 2 (BMP-2) is a negative regulator of SMC growth, but the mechanism by which it counteracts proliferation induced by growth factors (i.e., PDGF-BB, EGF) associated with pulmonary arterial hypertension $(\mathrm{PAH})(1,2)$ remains to be characterized. Loss-of-function-mutations in the BMP receptor II (BMP-RII) gene occur in 50\%-60\% of patients with familial PAH (FPAH) (3-5), 10\%-20\% of patients with idiopathic PAH (IPAH), and $6 \%-9 \%$ of patients with secondary forms of PAH associated with anorexic drug use (fenfluramine derivates) or congenital heart defects (APAH) $(6,7)$. However, independent of a mutation, patients with IPAH/FPAH (formerly called "primary PH"), and even those with APAH (formerly called "secondary" PAH), albeit to a lesser extent, have reduced pulmonary expression of BMP-RII (8). Thus, there are likely environmental modifiers and additional genetic factors that contribute to the decreased expression and function of BMP-RII in association with the development of PAH. This would suggest that it might be possible to rescue the adverse sequelae of reduced expression and antimitogenic signaling of BMP-RII by manipulating its downstream effectors to advantage.

Two potential downstream effectors of BMP-RII signaling are the transcription factor PPAR $\gamma$ and its putative target apoE (9). Interestingly, mRNA expression of both factors, in addition to BMP-2, is decreased in lung tissues from PAH patients $(8,10,11)$. PPARs are ligand-activated transcription factors belonging to the nuclear

Nonstandard abbreviations used: BMP-2, bone morphogenetic protein 2; BMP-RII, BMP receptor II; FPAH, familial PAH; HPASMC, human PASMC; PAH, pulmonary arterial hypertension; PASMC, pulmonary artery SMC; RVSP, RV systolic pressure. Conflict of interest: The authors have declared that no conflict of interest exists. Citation for this article: J. Clin. Invest. 118:1846-1857 (2008). doi:10.1172/JCI32503. receptor superfamily. Upon ligand activation, PPARs heterodimerize with the retinoid $X$ receptor (RXR) and bind to PPAR response elements (PPREs) in regulatory promoter regions of their target genes $(12,13)$. PPARs can also interact with signaling molecules to regulate gene expression independent of DNA binding (13). For example, PPAR $\gamma$ impairs phosphorylation (i.e., activation) of ERK $(14,15)$, a MAPK downstream of PDGF-BB/PDGFR- $\beta$ signaling implicated in SMC proliferation and migration (12).

There is supporting evidence that links PPAR $\gamma$ with transcription of apoE. A functional PPAR $\gamma$ response element is present in the apoE promotor (9), conditional disruption of the PPAR $\gamma$ gene (Pparg) in mice results in decreased apoE expression in macrophages (16), and PPAR $\gamma$ activation leads to apoE $\mathrm{mRNA}$ expression and protein secretion in an adipocyte cell line (17). apoE inhibits PDGF-BB-mediated SMC proliferation and migration $(18,19)$ by binding to LDL receptor-related protein (LRP) and internalizing the PDGFR- $\beta(20,21)$. Heightened arterial PDGF-BB/MAPK signaling is not only evident in apoE $\mathrm{E}^{-/-}$mice (22), but is also a key clinical feature of pulmonary vascular disease underlying $\mathrm{PAH}(2,23,24)$.

We have recently shown that insulin-resistant apoE-deficient $\left(\mathrm{apoE}^{-/-}\right)$mice on a high-fat diet develop PAH. However, the fact that a PPAR $\gamma$ agonist reversed PAH in this model (25) suggests that PPAR $\gamma$ targets independent of apoE are also important in suppressing pulmonary vascular remodeling. The antidiabetic drugs rosiglitazone and pioglitazone, both PPAR $\gamma$ ligands of the thiazolidinedione (TZD) class, inhibit PDGF-BB-induced SMC proliferation and migration in culture and in animal models of systemic cardiovascular disease (reviewed in ref. 12). Because of these and additional antiinflammatory and proapoptotic effects of PPAR $\gamma$ activation (reviewed in ref. 12), PPAR $\gamma$ agonists may be useful in the future treatment of PAH. 
Here, we report for the first time to our knowledge that both PPAR $\gamma$ and apoE act downstream of BMP-2/BMP-RII in primary cells (human and murine pulmonary artery SMCs [PASMCs]) and prevent SMC proliferation in response to PDGF-BB. BMP-2-mediated PPAR $\gamma$ activation occurs earlier than $S m a d 1 / 5 / 8$ phosphorylation and therefore appears to be independent of this established signaling axis downstream of BMP-RII. BMP-2 induces a decrease in nuclear phospho-ERK, and rapid nuclear shuttling and DNA binding of PPAR $\gamma$, whereas PDGF-BB has the opposite effects. Both BMP2 and the PPAR $\gamma$ agonist rosiglitazone stimulate production and secretion of apoE in PASMCs. Using short hairpin RNAi in human PASMCs (HPASMCs), PASMCs from a patient with FPAH and a mutation in BMP-RII (W9X), a PPAR $\gamma$ antagonist, and PASMCs lacking PPAR $\gamma$ or apoE, we demonstrate that the antiproliferative effect of BMP-2 is BMP-RII, PPAR $\gamma$, and apoE dependent. Consistent with these data, we show that mice with deletion of PPAR $\gamma$ in SMCs (SM22 $\alpha$ Cre PPAR $\gamma^{f l o x} / f l o x$ mice) spontaneously develop PAH. Taken together, our results reveal a novel PPAR $\gamma / \mathrm{apoE}$ axis downstream of BMP-2 signaling that could explain the antiproliferative effect of BMP-RII activation in HPASMCs. Our data also suggest that PPAR $\gamma$ agonists might reverse SMC proliferation and vascular remodeling in $\mathrm{PAH}$ patients with or without BMP-RII dysfunction.

\section{Results}

Additional results are provided in the supplemental material (available online with this article; doi:10.1172/JCI32503DS1).

$B M P-2-$ mediated inbibition of HPASMC proliferation requires BMP-RII, $P P A R \gamma$, and apoE. For long-term gene silencing of human BMP-RII, we constructed a pLentivirus 6 with an integrated short hairpin oligonucleotide directed against the mRNA of human BMP-RII (shRNAi). We confirmed, by quantitative RT-PCR, an $85 \%$ stable knockdown of BMP-RII mRNA in shBMP-RIIi versus shLacZi (control) transfected HPASMCs (Supplemental Figure 1). Recombinant BMP-2 $(10 \mathrm{ng} / \mathrm{ml})$ inhibited PDGF-BB-induced proliferation in LacZi control but not in shBMR-RIIi HPASMCs as judged by cell counts (Figure 1). Results of MTT proliferation assays shown in Supplemental Figure 2 are consistent with cell counts. We reproduced the growth-inhibitory effect of BMP-2, with the same low concentration $(10 \mathrm{ng} / \mathrm{ml})$ of BMP-4 and -7 , although BMP-7 appeared to have a weaker effect than BMP-2 and -4. Furthermore, with siBMP-RII (knockdown), there was less growth inhibition in response to BMP-2, -4 , and -7 (Supplemental Figure 3 ). We also confirmed that siBMP-RII abolished BMP-2-induced phosphorylation of Smad1/5/8 (Supplemental Figure 4).

We then showed that the BMP-2-mediated inhibition of PDGF-BBinduced HPASMC proliferation requires not only BMP-RII, but also PPAR $\gamma$. First, the antimitogenic effect of BMP-2 could be reproduced by the PPAR $\gamma$ agonist rosiglitazone $(1 \mu \mathrm{M})$ (Figure $1 \mathrm{~B})$. Second, the antiproliferative effect of BMP-2 was lost in the presence of the irreversible PPAR $\gamma$ antagonist GW9662 (Figure 1C). Finally, BMP-2-mediated inhibition of PDGF-BB-induced cell proliferation was not observed in murine PASMCs with deletion of PPAR $\gamma$ but was found in PASMCs from littermate controls (Figure 1D). To address whether the effect of PPAR $\gamma$ could be mediated by induction of apoE, we first established that a physiological dose of recombinant apoE $(10 \mu \mathrm{M})$ completely blocked PDGF-BB-induced proliferation of HPASMCs (Figure 1E). Moreover, the growth-inhibitory effect of BMP-2 on PDGF-BB-induced cell proliferation was lost in PASMCs from apoE $\mathrm{E}^{-/-}$mice (Figure $1 \mathrm{~F})$. Taken together, these data support the presence of a novel antiproliferative axis downstream of BMP-2 that requires BMP-RII signaling, PPAR $\gamma$ activation, and production of apoE, a lipoprotein not previously known to be synthesized by SMC. Documentation of apoE production and secretion in HPASMCs in response to BMP-2 and rosiglitazone is described below.

Opposing effects of PDGF-BB and BMP-2 on phospho-ERK and PPAR $\gamma$ activation in HPASMCs. We next determined whether BMP-2 and PDGF-BB might have opposing effects on the subcellular localization of phospho-ERK and PPAR $\gamma$ that would explain their functional antagonism in PASMCs. PPAR $\gamma$ has been shown to activate phosphatases and prevent ERK phosphorylation in vascular SMCs (14, 15). In addition, PPAR $\gamma$ activation can directly inhibit PDGF-BBmediated phospho-ERK activity (26) by blocking its nuclear translocation (27). Conversely, PDGF-BB/PDGFR- $\beta$-mediated phosphorylation of ERK leads to phosphorylation and thereby inactivation of PPAR $\gamma$ at its $\mathrm{N}$ terminus (28).

PDGF-BB stimulated a 3- to 5-fold increase in phospho-ERK1/2 in nuclear extracts and a 4-fold rise in phospho-ERK1 in cytoplasmic extracts (Figure 2A). BMP-2, however, led to a rapid decrease in phospho-ERK1/2 in nuclear extracts (Figure 2B) and significantly reduced phospho-ERK2 in cytoplasmic extracts (Figure 2B). PDGF-BB rapidly and transiently decreased nuclear protein levels and DNA binding of PPAR $\gamma$. This decrease in PPAR $\gamma$ DNA binding (Figure 2C, upper panel) temporally coincided with the rapid appearance of phospho-ERK1/2 in the nucleus upon PDGF-BB stimulation (maximum at 5-10 min; Figure 2A). There was no significant change in PPAR $\gamma$ levels in cytoplasmic extracts (Figure 2C). In contrast to PDGF-BB, BMP-2 induced a rapid and marked increase in PPAR $\gamma$ DNA binding (Figure 2D) associated with elevated levels of PPAR $\gamma$ protein in nuclear extracts. This could represent stabilization of PPAR $\gamma$, but since PPAR $\gamma$ tended to be concomitantly lower in cytoplasmic extracts, transient nuclear shuttling of PPAR $\gamma$ is also likely (Figure 2D). Of note, BMP-2-mediated PPAR $\gamma$ activation in HPASMCs (Figure 2, B and D) occurred earlier than phosphorylation of Smad1/5/8 (Supplemental Figure 4). Therefore, phosphoSmad1/5/8 does not appear to mediate DNA binding of PPAR $\gamma$.

Interestingly, when we prepared total cell lysates containing the cytoplasmic membrane fraction, we found that BMP-2 induces rapid ERK1/2 phosphorylation (Supplemental Figure 5A). This fraction is absent in nuclear and cytoplasmic extract preparations due to high spin steps. We showed by immunohistochemistry that concomitant with the rapid decrease in phospho-ERK1/2 in the nucleus (shown by Western immunoblot in Figure 2B), BMP-2 led to strong phospho-ERK1/2 staining at the cytoplasmic membrane (Supplemental Figure 5B). It has been previously demonstrated in other cell types that phospho-ERK binds to cytoplasmic membrane proteins such as the receptor for advanced glycation end products (29).

BMP-2 and a PPAR $\gamma$ agonist inhibit PDGF-BB signaling in HPASMCs. We next determined whether BMP-2 and PPAR $\gamma$ activation inhibit PDGF-BB-induced MAPK pathways (i.e., phospho-ERK1/2). BMP-2 inhibited PDGF-BB-induced nuclear and cytoplasmic ERK phosphorylation (Figure 3A). BMP-2 also prevented PDGF-BB-mediated inhibition of PPAR $\gamma$ DNA binding. In fact an increase in PPAR $\gamma$ DNA binding was observed with BMP-2 despite concomitant PDGF-BB stimulation (Figure 3B). Moreover, 24-hour preincubation with the PPAR $\gamma$ agonist rosiglitazone significantly reduced and delayed PDGF-BB-induced ERK phosphorylation in total cell lysates (Figure 3C). Hence, BMP-2 and the PPAR $\gamma$ agonist rosiglitazone act as functional antagonists of PDGF-BB signaling by inhibiting ERK1/2 phosphorylation. 

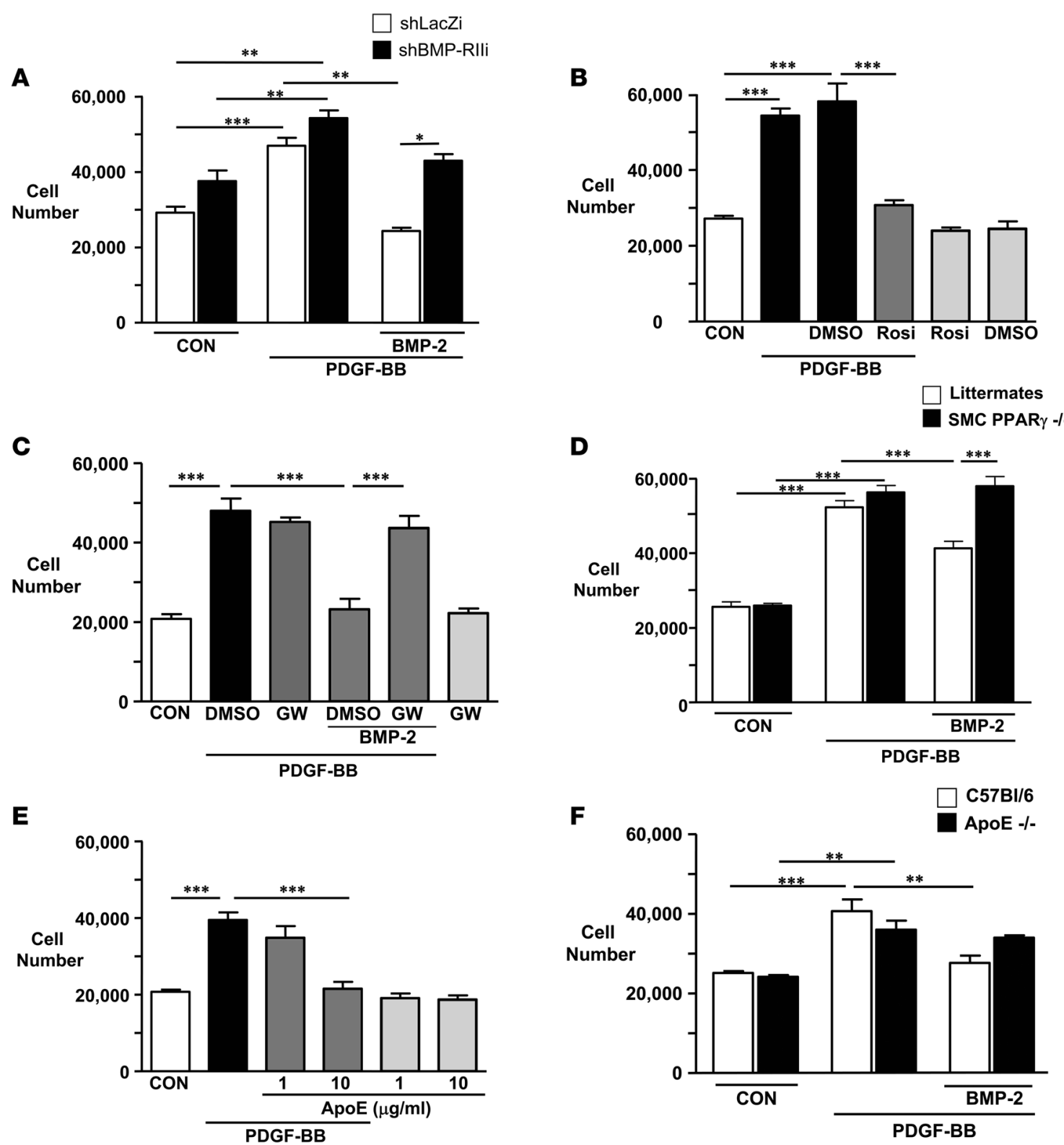

Figure 1

Antiproliferative effects of BMP-2 (A, C, D, and F), the PPAR $\gamma$ agonist rosiglitazone (Rosi; $\mathbf{B})$, and apoE (E) on PDGF-BB-induced proliferation of human (A, B, C , and E) and murine (D and F) PASMCs. PASMCs were seeded at $2.5 \times 10^{4}$ cells per well of a 24 -well plate in $500 \mu$ l of growth medium and allowed to adhere overnight. The cells were washed with PBS prior to the addition of starvation media (0.1\% FBS) and incubated for 24 hours (murine PASMCs) or 48 hours (HPASMCs) and then stimulated with PDGF-BB $(20 \mathrm{ng} / \mathrm{ml})$ for 72 hours. BMP-2 (10 ng/ml), rosiglitazone $(1 \mu \mathrm{M})$, and recombinant human apoE $(1-10 \mu \mathrm{M})$ were added to quiescent cells 30 minutes prior to PDGF-BB stimulation. The PPAR $\gamma$ antagonist GW9662 (GW; $1 \mu \mathrm{M})$ was added 24 hours prior to the addition of BMP-2. Cells were finally washed twice with PBS, trypsinized, and counted in a hemacytometer (4 counts per well). Cell numbers in controls at time points 0 (CON) and 72 hours were not significantly different. A: shLacZi, HPASMCs transfected with short hairpin LacZi pLentivirus 6 (control); shBMP-RIli, HPASMCs transfected with short hairpin pLentivirus 6 BMP-RIli (i.e., BMP-RII-deficient PASMCs). D: Littermates, littermate control PASMCs; SMC PPAR $\gamma^{-1-}$, PASMCs isolated from SM22 $\alpha$ Cre PPAR $\gamma^{\text {flox }}$ fllox mice. F: C57BL/6, control murine PASMCs; apoE ${ }^{-/}$, PASMCs isolated from apoE-deficient mice. Bars represent mean \pm SEM $(n=3$ in A, D, and F; $n=4$ in $\mathbf{B}$ and $\mathbf{C} ; n=6$ in $\mathbf{E} ; n=12$ in controls of $\mathbf{A}) .{ }^{*} P<0.05 ;{ }^{* *} P<0.01 ;{ }^{* \star *} P<0.001$ as indicated; ANOVA with Bonferroni's multiple comparison test.

Rosiglitazone blocks PDGF-BB-induced proliferation of BMP-RII mutant HPASMCs. We next investigated whether PPAR $\gamma$ activation could inhibit PDGF-BB-induced proliferation of HPASMCs with a loss-of-function mutation in the BMP-RII. Therefore, we isolated PASMCs from the explanted lung of a patient with FPAH known to harbor a frameshift mutation in BMP-RII. BMP-2 inhibited PDGF-BB-induced proliferation in WT but not BMP-RII mutant HPASMCs (Figure 4). In contrast, the PPAR $\gamma$ agonist rosiglitazone blocked PDGF-BB-induced proliferation in both WT and BMP-RII mutant cells so that cell numbers were similar to those in unstim- 

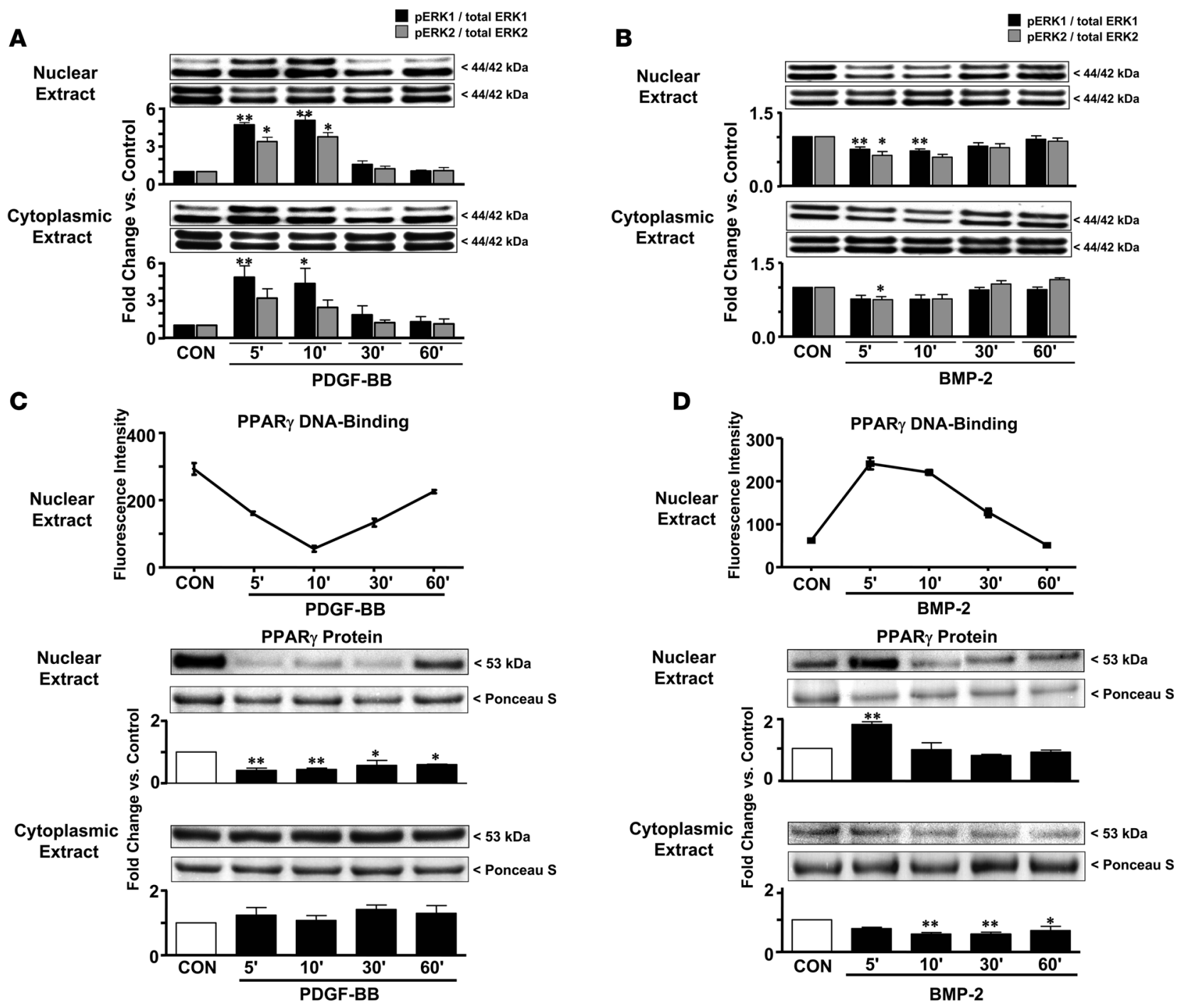

Figure 2

PDGF-BB (A and $\mathbf{C})$ and BMP-2 (B and $\mathbf{D})$ have opposing effects in HPASMCs on protein levels of phospho-ERK/total ERK (A and B), PPAR $\gamma$ DNA binding in nuclear extracts (upper panels in $\mathbf{C}$ and $\mathbf{D}$ ), and PPAR $\gamma$ protein in nuclear and cytoplasmic extracts (lower panels in $\mathbf{C}$ and $\mathbf{D}$ ). Cells were stimulated with PDGF-BB $(20 \mathrm{ng} / \mathrm{ml})$ or BMP-2 $(10 \mathrm{ng} / \mathrm{ml})$ as described in the legend for Figure 1. In separate experiments, we determined that neither of the solvents (DMSO, sterile water; both 1:10,000) influenced the results. Western immunoblotting and PPAR $\gamma$ DNA binding assays are described in Methods. For the PPAR $\gamma$ DNA binding assay, bars represent median \pm SEM of triplicate measurements of 1 representative experiment of 2 (C) and 3 (D) independent experiments with similar results. For protein levels in cell fractions, bars represent mean $\pm \operatorname{SEM}(n=3-4) .{ }^{*} P<0.05 ;{ }^{* *} P<0.01$ versus control; ANOVA with Dunnett's post-hoc test.

ulated controls (Figure 4). BMP-2 and rosiglitazone, in the (low) concentrations used, had no significant effect on the basal cell proliferation rate (Figure 4). Thus, PPAR $\gamma$ agonists have the potential to rescue the growth-inhibitory effect of BMP-2 in PASMCs with BMP-RII dysfunction.

BMP-2 and rosiglitazone induce apoE expression and secretion in HPASMCs. Since the growth-inhibitory effect of BMP-2 is absent in apoE-deficient PASMCs (Figure 1F), we hypothesized that apoE might be a transcriptional target of BMP-2-activated PPAR $\gamma$ in SMCs. Indeed, both BMP-2 and rosiglitazone induced apoE protein expression (cell lysates) and secretion (supernatant) in HPASMCs (Figure 5A). Moreover, the BMP-2-mediated upregulation of apoE protein was reduced by half in PASMCs harvested from SM22 $\alpha$ Cre
PPAR flox/flox mice (Figure 5B). This suggests that the induction of apoE expression by BMP-2 is to a great extent PPAR $\gamma$ dependent.

Creation of mice with targeted deletion of PPAR in arterial SMCs (SM22 $\alpha$

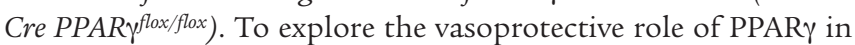
preventing the development of PAH in an intact animal, we investigated a transgenic mouse with targeted deletion of PPAR $\gamma$ in arterial SMCs $\left(S M 22 \alpha\right.$ Cre PPAR $\left.\gamma^{f l o x} / f l o x\right)$. We documented, by PCR, gain of a new knockout transcript (300 bp) and almost complete loss of the 700-bp wild-type transcript in PASMCs and aorta isolated from SM22 $\alpha$ Cre PPAR $\gamma^{f l o x} /$ flox mice (Figure 6A). Both the wild-type and the knockout transcript were found in lungs from $S M 22 \alpha$ Cre $P P A R \gamma^{f l o x} / f l o x$ mice, since the tissue contains several cell types besides SMCs. In contrast, only the wild-type transcript was detected in lung 
A

Nuclear Extract
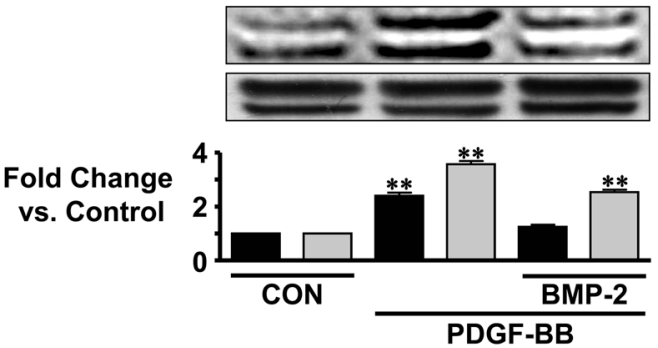

B

Nuclear Extract PPAR $\gamma$ DNA-Binding

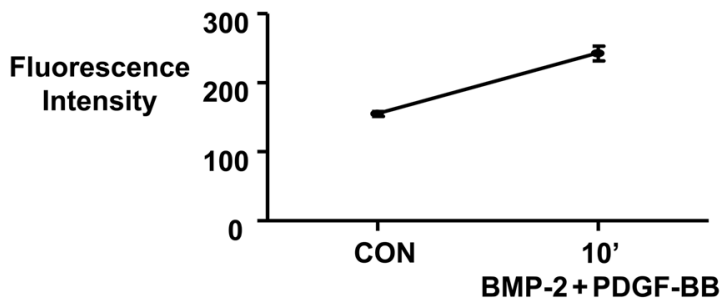

Cytoplasmic Extract
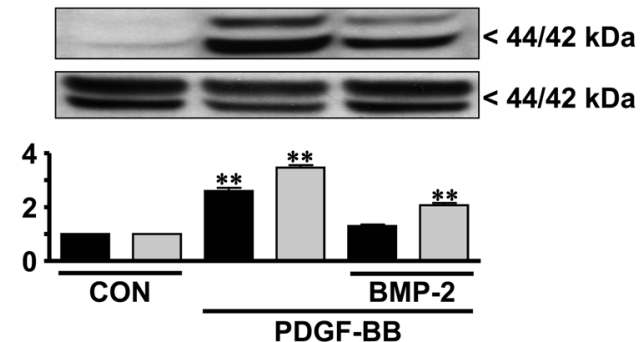

C

$\frac{\text { DMSO }}{\frac{\text { PDGF-BB }}{\text { 5 }^{\prime} 10^{\prime} 30^{\prime} 60^{\prime}}} \frac{\text { Rosi }}{\frac{\text { PDGF-BB }}{5^{\prime} 10^{\prime} 30^{\prime} 60^{\prime}}}$

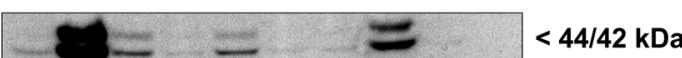

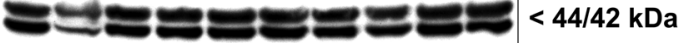

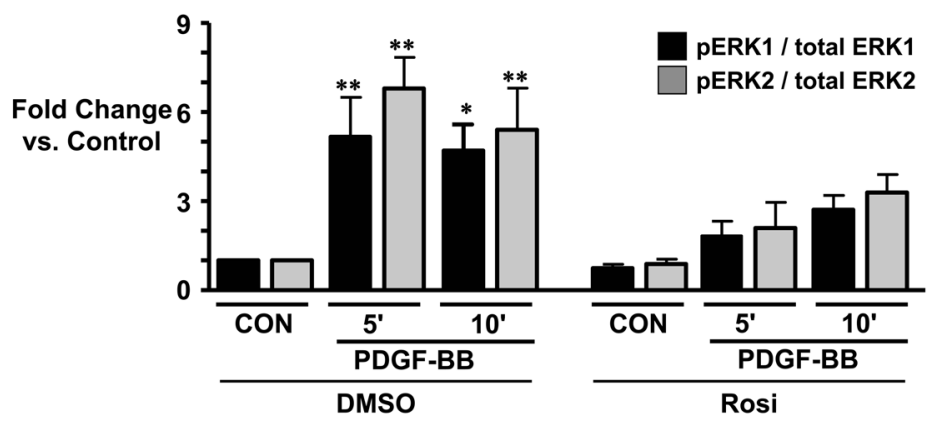

Figure 3

BMP-2 and rosiglitazone inhibit PDGF-BB-mediated ERK phosphorylation (A and C), and concomitant BMP-2 and PDGF-BB stimulation increases PPAR $\gamma$ DNA binding (B), in HPASMCs. Cells were preincubated with BMP-2 $(10 \mathrm{ng} / \mathrm{ml})$ for 30 minutes (A and B) or rosiglitazone $(1 \mu \mathrm{M})$ for 24 hours $(\mathbf{C})$, followed by PDGF-BB $(20 \mathrm{ng} / \mathrm{ml})$ stimulation for 10 minutes $(\mathbf{A}$ and $\mathbf{B})$ or $5-60$ minutes. (C) Western immunoblotting and PPAR $\gamma$ DNA binding assays are described in Methods and Figure 2. For protein levels in cell fractions (A) or cell lysates (C), bars represent mean \pm SEM $(n=3$ each). In C, all samples are compared with the DMSO control. For the PPAR $\gamma$ DNA binding assay (B), bars represent median \pm SEM of triplicate measurements of 1 representative experiment of 3 independent experiments with similar results. ${ }^{\star} P<0.05$; ${ }^{\star \star} P<0.01$ versus control; ANOVA with Dunnett's post-hoc test.

tissue from littermate control mice (Figure 6A). We also confirmed knockout of PPAR $\gamma$ protein in PASMCs from SM22 $\alpha$ Cre PPAR $\gamma$ flox/flox mice (Figure 6B). BMP-2 stimulation of these murine PPAR $\gamma$-deficient PASMCs revealed intact phospho-Smad $1 / 5 / 8$ signaling that occurred earlier (5-10 minutes; Figure 6C) than in human control PASMCs, where it was observed at 30 minutes (Supplemental Figure 4). Hence, the established BMP-2/phospho-Smad1/5/8 signaling pathway appears to be independent of PPAR $\gamma$, since it occurs in PASMCs with deletion of PPAR $\gamma$ (Figure 6C).

Mice with targeted deletion of PPAR in arterial SMCs (SM22 $\alpha$ Cre PPAR $\gamma^{f l o x}$ flox) have PAH. SM22 $\alpha$ Cre PPAR flloxflox mice had elevated RV systolic pressure (RVSP) in room air when compared with controls (29.0 versus $21.5 \mathrm{mmHg}$; $P<0.001$; Figure 7A). Systemic blood pressure, RV function (RV $d P / d t$ maximum and minimum) and LV function (fractional shortening, ejection fraction), and cardiac output were not significantly different when comparing the 2 groups (Table 1 ). In association with elevated RVSP as a measure of PAH, SM22 $\alpha$ Cre $P P A R \gamma^{f l o x / f l o x}$ mice also developed RV hypertrophy (RVH), as judged by the ratio of RV weight to that of the LV and septum $(0.46$ versus 0.26 ; $P<0.0001$; Figure 7B) and the ratio of RV to body weight $(P<0001$; Table 1). SM22 $\alpha$ Cre PPAR $\gamma^{\text {flox } f l o x}$ mice had a similar number of pul- monary arteries per 100 alveoli (Table 1) and per surface area (data not shown) but showed more muscularized pulmonary arteries at the alveolar wall level, when compared with littermate controls (Figure 7, $\mathrm{C}-\mathrm{E})$. The muscular thickening in small pulmonary arteries seen in lung sections from SMC PPAR $\gamma$-deficient mice (Movat staining; Figure 7, D and E) was confirmed by immunohistochemistry with specific antibodies for $\alpha$-SMA (Figure 7, F and G) and associated with an enhanced signal for proliferating cell nuclear antigen (PCNA; Figure 7, $\mathrm{H}$ and I) in PASMCs. LV end-diastolic inner diameter (LVIDD), LV end-diastolic posterior wall thickness (LVPWd), and end-diastolic interventricular septum thickness (IVSd) as measures of LV dilatation and LV hypertrophy (LVH) were not different between the 2 genotypes (Table 1). Thus, LV dysfunction does not account for the

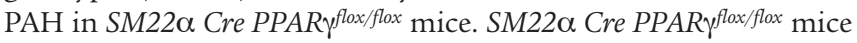
had similar hematocrit and glucose values but slightly higher wbc counts than controls (Table 1).

\section{Discussion}

This report is the first indication to our knowledge that the antiproliferative effects of BMP-2/BMP-RII signaling in primary cells (i.e., PASMCs) can be attributed to activation of PPAR $\gamma$ and its 


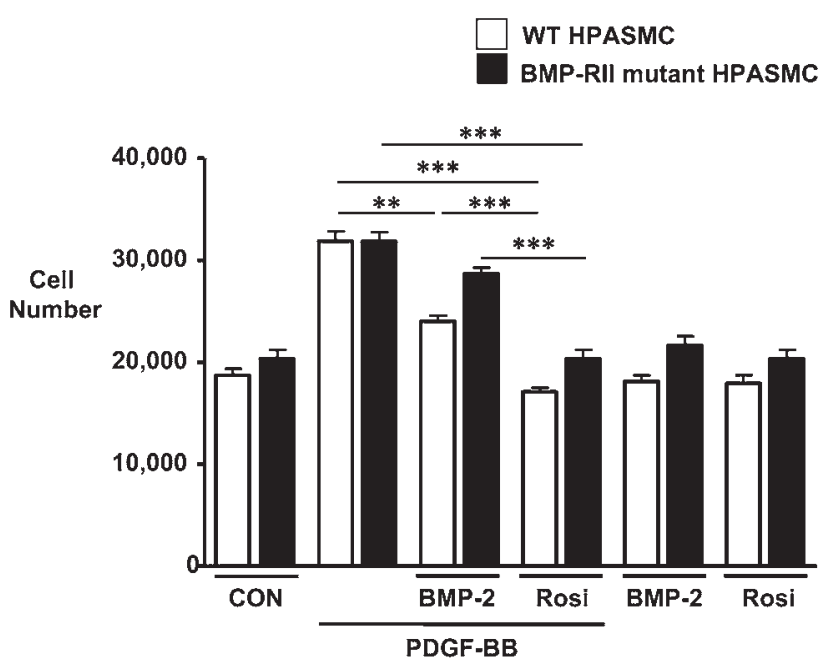

putative transcription target apoE, a protein not previously known to be synthesized and secreted by SMCs (Figure 8A). Furthermore, we establish that endogenous expression of PPAR $\gamma$ in SMCs can protect against the spontaneous development of PAH. Our experiments using a PPAR $\gamma$ antagonist and PPAR $\gamma$-deficient PASMCs further demonstrate that PPAR $\gamma$ is required for BMP-2-mediated inhibition of PASMC proliferation induced by PDGF-BB. By using RNAi and PASMCs with a known loss-of-function mutation of BMP-RII, we show that BMP-2 requires BMP-RII to block SMC
Figure 4

Antiproliferative effects of BMP-2 and the PPAR $\gamma$ agonist rosiglitazone on PDGF-BB-induced proliferation of human wild-type and BMP-RII mutant PASMCs. Control PASMCs were isolated from surgical resection specimens derived from patients undergoing lobectomy or pneumonectomy for suspected lung tumor. Additional peripheral pulmonary arteries $(<1-2 \mathrm{~mm}$ external diameter) were obtained from a patient undergoing heart-lung transplantation for FPAH and known to harbor a mutation (W9X) in BMP-RII. The nature of the BMP-RII mutation, cell isolation, culture techniques, and cell counts are described in Methods and in Figure 1. HPASMCs were incubated for 48 hours in starvation media $(0.1 \%$ FBS $)$ and then stimulated with PDGF-BB $(20 \mathrm{ng} / \mathrm{ml})$ for 72 hours. BMP-2 $(10 \mathrm{ng} / \mathrm{ml})$ or rosiglitazone $(1 \mu \mathrm{M})$ were added to quiescent cells 30 minutes prior to PDGF-BB stimulation. Bars represent mean \pm SEM $(n=3) .{ }^{* *} P<0.01$; ${ }^{* * *} P<0.001$ as indicated; ANOVA with Bonferroni's multiple comparison test. The number of PDGF-BB-stimulated cells was significantly higher than that of untreated control cells $(P<0.001)$.

proliferation and provide evidence that BMP-RII dysfunction that occurs with or without BMP-RII mutations $(3,4)$ could lead to unopposed mitogenic SMC stimulation by PDGF-BB and other growth factors (Figure 8B). BMP-RII dysfunction may, however, be rescued by PPAR $\gamma$ agonists such as pioglitazone or rosiglitazone (Figure 8C), as we have demonstrated in PDGF-BB-stimulated BMP-RII mutant HPASMCs.

In this study, we investigated whether BMP-2 and PDGF-BB might have opposing effects on the growth-inhibitory transcrip-
A

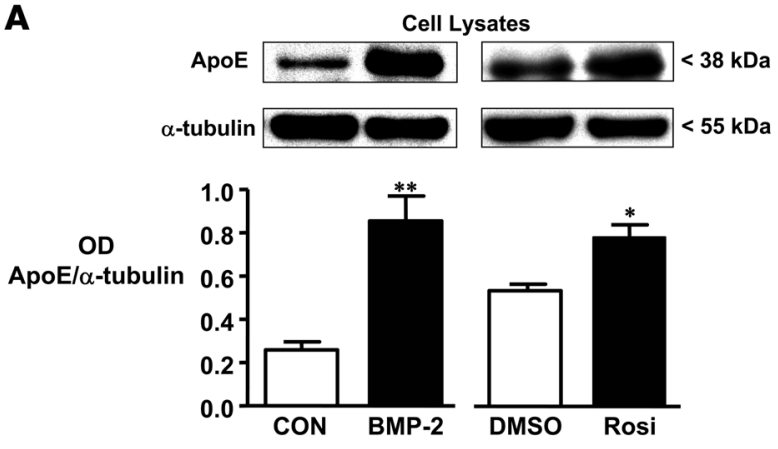

B

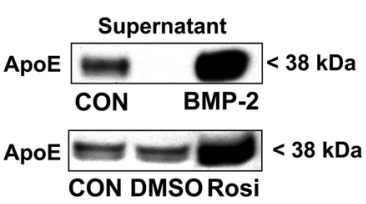

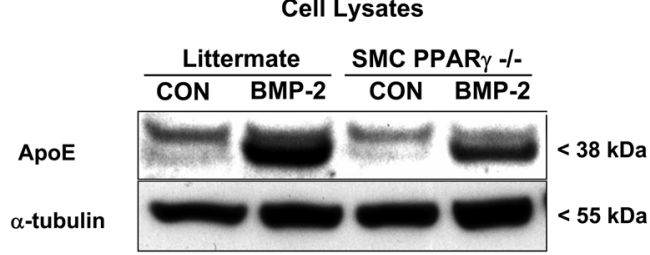

Figure 5

BMP-2 and the PPAR $\gamma$ agonist rosiglitazone induce apoE in PASMCs. (A) apoE protein expression in cell lysates (left) and apoE protein secretion in supernatant (right) induced by BMP-2 $(10 \mathrm{ng} / \mathrm{ml}, 24$ hours) and rosiglitazone $(1 \mu \mathrm{M}, 24$ hours) were detected by immunoblotting as described in Methods (for cell lysates, densitometric values were corrected for equal loading using $\alpha$-tubulin). For apoE secretion, the media of 3-4 cell culture flasks per condition were pooled and concentrated for the blots shown (representative of 2 independent experiments with similar results). (B) BMP-2-induced (10 ng/ml, 24 hours) upregulation of apoE in murine control PASMCs was reduced by half in PASMCs har-

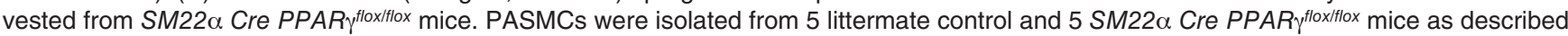
in Methods. PASMCs from each genotype were then pooled and subcultured prior to stimulation with BMP-2. The blot is representative of 2 independent experiments with similar results. For apoE protein levels in cell lysates $(\mathbf{A})$, bars represent mean $\pm \mathrm{SEM}(n=3)$. ${ }^{\star} P<0.05$; ${ }^{* *} P<0.01$ versus control; unpaired 2 -tailed $t$ test. 
A

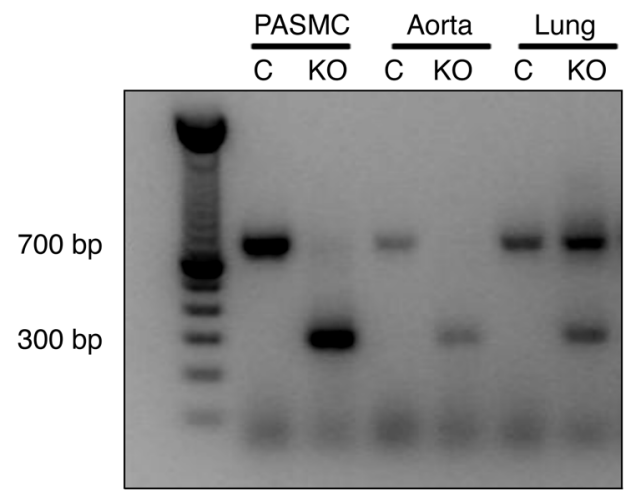

B

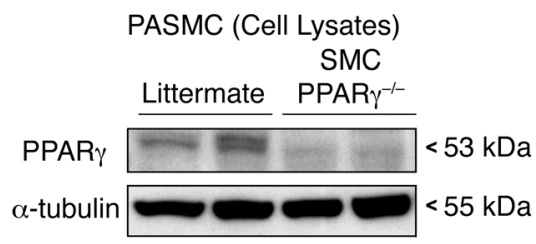

\section{Figure 6}

Mice with targeted deletion of PPAR in SMCs maintain BMP-2induced pSmad1/5/8 signaling. (A and B) Genotyping of mice with targeted deletion of PPAR $\gamma$ in SMCs. (A) PCR reactions showing gain of a 300-bp knockout transcript and almost complete loss of the 700-bp wild-type transcript in PASMCs and aorta from SM22 $\alpha$ Cre PPAR flloxflox mice. In the lung, which contains SMCs but also many other cell types, both transcripts are found in SM22 $\alpha$ Cre PPAR floxflox mice, whereas only the wild-type transcript is detected in littermate control mice. (B) Western immunoblotting of PASMC lysates isolated from both littermate and SM22 $\alpha$ Cre PPAR $\gamma^{\text {flox } / \text { flox }}$ (SMC PPAR $\gamma^{-1-}$ ) mice ( $n=2$ each) showed no detectable PPAR $\gamma$ protein expression when compared with control cells. (C) Both littermate control and SMC PPAR $\gamma^{-1-}$ PASMCs were stimulated with BMP-2 $(10 \mathrm{ng} / \mathrm{ml})$ for $5-60$ minutes as described in the legend for Figure 1 , and phospho-Smad 1/5/8 protein expression was detected by immunoblotting as described in Methods (densitometric values were corrected for equal loading using $\alpha$-tubulin). Data for 1 of 2 representative experiments with similar results are shown.

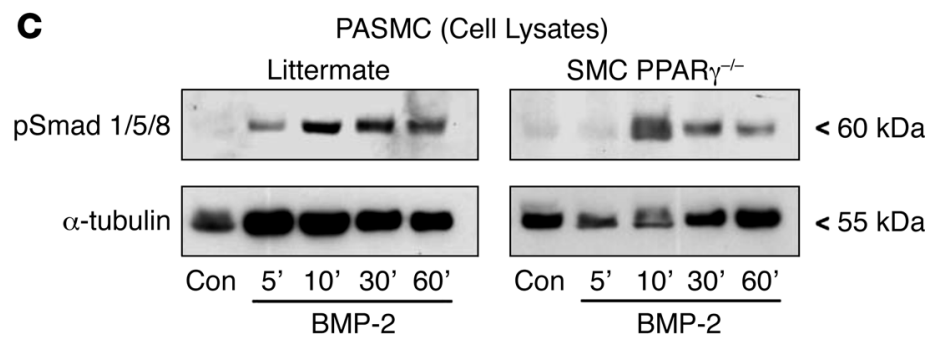

tion factor PPAR $\gamma$ and the growth-promoting MAPK nuclear phospho-ERK (30). We observed that BMP-2 activation of PPAR $\gamma$ in HPASMCs was independent of the phospho-Smad1/5/8 pathway but correlated with reduced nuclear phospho-ERK expression, presumably due to PPAR $\gamma$ activation of phosphatases $(14,15)$ or inhibition of phospho-ERK nuclear translocation (27). Conversely, PDGF-BB/PDGFR- $\beta$-mediated induction of nuclear phosphoERK was associated with reduced PPAR $\gamma$ DNA binding, probably due to phosphorylation and inactivation of PPAR $\gamma$ at its $\mathrm{N}$ terminus (28) and/or enhancement of nuclear export (31) or ubiquitin/ proteasome-mediated degradation and rapid turnover of PPAR $\gamma$ (32). Thus, it may be that continuous endogenous BMP-2/BMPRII signaling is necessary as a gatekeeper to prevent inactivation of PPAR $\gamma$ and nuclear translocation of phospho-ERK in response to PDGF-BB/PDGFR- $\beta$ stimulation.

Low-dose rosiglitazone and a physiological dose of recombinant apoE completely blocked PDGF-BB-induced proliferation of HPASMCs, consistent with previous work in systemic SMCs $(12,33)$. Since we showed that both BMP-2 and rosiglitazone induce apoE protein synthesis and secretion in HPASMCs, we reason that, in addition to lowering phospho-ERK in the nucleus, PPAR $\gamma$-mediated induction of apoE inhibits PDGF-BB/PDGFR- $\beta$ signaling $(20,21)$. The fact that some upregulation of apoE by BMP- 2 occurs even in PPAR $\gamma$-deficient SMCs indicates that apoE also can be regulated by a PPAR $\gamma$-independent pathway. Further studies using apoE promoter-reporter assays would delineate the nature of PPAR $\gamma$-mediated transcriptional activation of this target gene.
The spontaneous development of PAH in the SM22 $\alpha$ CrePPAR $\gamma^{\text {flox/flox }}$ mice is in contrast to our observations that $\mathrm{apoE}^{-/-}$mice at similar age develop PAH only when fed a high-fat diet leading to insulin resistance (25). Since we found that the PPAR $\gamma$ agonist rosiglitazone can completely reverse $\mathrm{PAH}$ in the $\mathrm{apoE}^{-/-}$mouse, multiple other PPAR $\gamma$-dependent mechanisms in addition to apoE induction may prevent PASMC proliferation and PAH in response to growth factors. In our previous study, we attributed the rescue effect of PPAR $\gamma$ activation to enhanced production of adiponectin, an adipocytokine that sequesters the ligand PDGF-BB, thereby inhibiting SMC proliferation and survival (34). However, we have not been able to detect adiponectin mRNA or protein expression in HPASMCs. Nonetheless, activated PPAR $\gamma$ can induce multiple other growth-inhibitory and proapoptotic gene products and repress growth-promoting factors in vascular cells (Figure 8C). For example, PPAR $\gamma$ activation blocks PDGF gene expression (35) and induces the expression of LRP (36), the receptor necessary for apoE-mediated suppression of PDGF-BB signaling $(20,21)$ (Figure $8, \mathrm{~A}$ and $\mathrm{C}$ ). PPAR $\gamma$ activation also reduces levels of endothelin-1 (ET-1) (37) and the endogenous nitric oxide synthase inhibitor asymmetric dimethylarginine (ADMA) $(38,39)$, factors that are implicated in the pathobiology of PAH (39). Moreover, activated PPAR $\gamma$ stabilizes the cyclindependent kinase inhibitor P27 ${ }^{\mathrm{KIP} 1}$ (40) and inhibits telomerase activity (41), retinoblastoma protein phosphorylation (40), and ultimately $G_{1}$ to $S$ phase transition, cell-cycle progression, and vascular SMC proliferation (40). By blocking important survival pathways downstream of activated PDGFR- $\beta$, i.e., PI3K (42), 
A

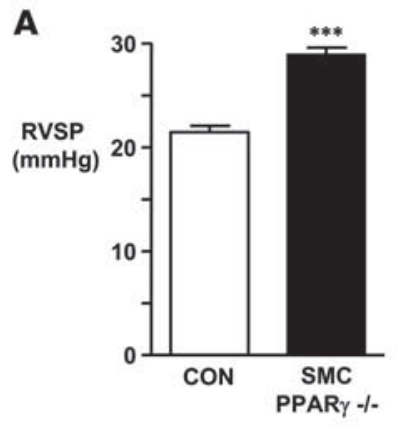

C

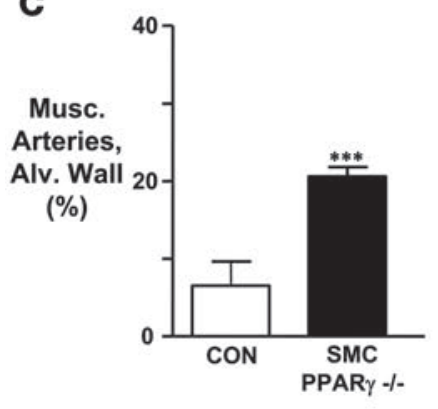

B

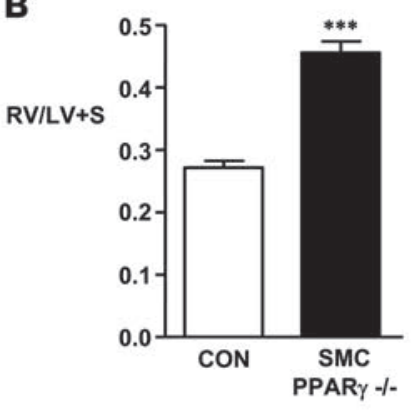

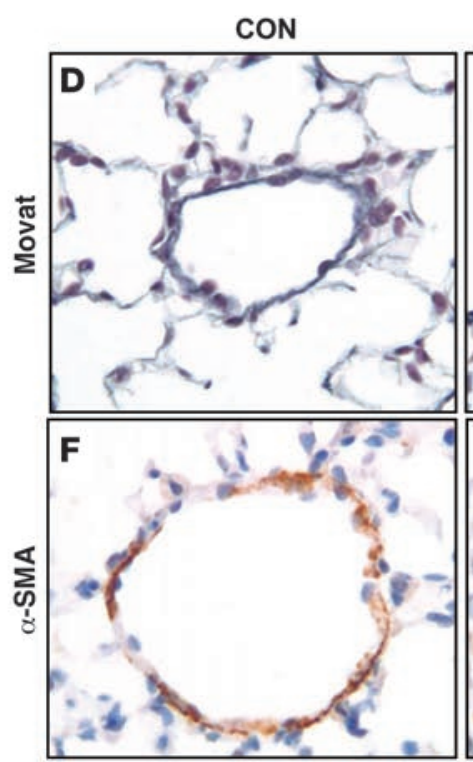
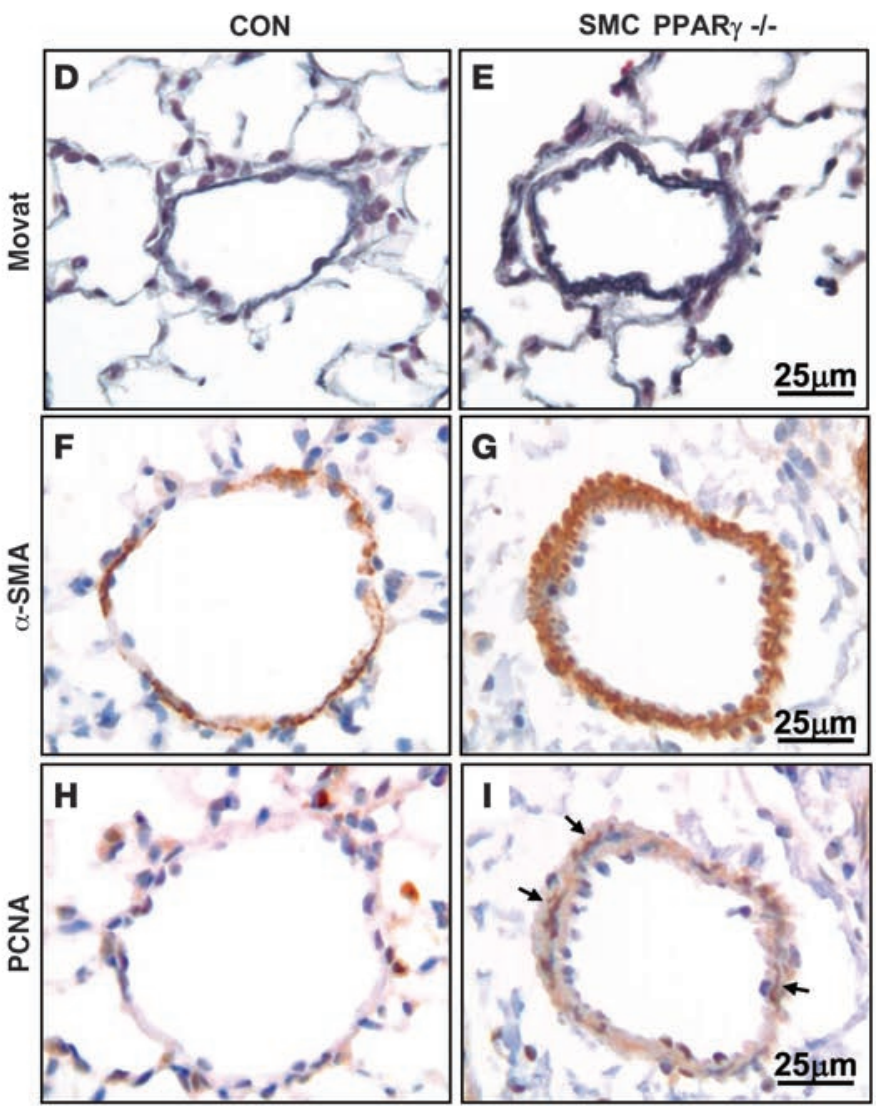

\section{Figure 7}

PAH in mice with targeted deletion of PPAR $y$ in SMCs. Thirteen- to 15-week-old mice underwent RV catheterization, followed by organ harvest. (A) RVSP measurements, as described in Methods. (B) Right ventricular hypertrophy (RVH), measured as ratio of the weight of the RV to that of the LV plus septum (RV/LV+S), as described in Methods. (C) Muscularization of alveolar wall arteries (Musc. Arteries Alv. Wall), as described in Methods. (D) Representative photomicrographs of lung tissue (stained by Movat pentachrome) of 15-week-old mice showing a typical nonmuscular peripheral alveolar artery in a littermate control mouse. (E) A similar section in the SM22 $\alpha$ Cre PPAR $\gamma^{\text {flox/fllox }}$ (SMC PPAR $\gamma^{-1-}$ ) mouse shows an alveolar wall artery surrounded by a rim of muscle. (F-I) Immunohistochemistry in serial lung tissue sections from littermate control (CON) and SMC PPAR $\gamma^{-1-}$ mice stained for $\alpha$-SMA (F and $\left.\mathbf{G}\right)$ and proliferating cell nuclear antigen (PCNA; $\mathbf{H}$ and $\left.\mathbf{I}\right)$. Arrows in I indicate enhanced PCNA staining in PASMCs. See also Table 1. Bars represent mean \pm SEM $(n=5)$. ${ }^{* \star} P<0.001$ versus control; unpaired 2-tailed $t$ test.

PPAR $\gamma$ agonists also lead to apoptosis of proliferating vascular cells $(12,43)$. In addition, it is known that PPAR $\gamma$ ligands impair production of matrix metalloproteinases (44) that can be activated by elastase (45). Our group has shown that inhibition of this proteolytic cascade not only prevents but also reverses advanced fatal PAH in rats (46).

Previous studies have shown beneficial effects of BMP-2 (47), PPAR $\gamma$ activation (reviewed in ref. 12), and apoE $(18,19)$ in preventing systemic vascular pathology, but our observations are the first indication to our knowledge that all 3 factors are linked. More recently, a connection between PPAR $\gamma$ and apoE has been made in patients with Alzheimer disease, in that the improvement of cognitive function with rosiglitazone is not apparent in patients who carry the APOE epsilon 4 allele (48). Hence, the novel axis we describe may be relevant in addressing mechanisms that underlie many different pathologic processes.

In summary, our data reveal a novel PPAR $\gamma /$ apoE axis downstream of BMP-2 signaling in HPASMCs. Failure to activate PPAR $\gamma$ in response to BMP-2 when there is BMP-RII dysfunction could place a patient at risk for the development or progression of $\mathrm{PAH}$.
We suggest that PPAR $\gamma$ agonists might rescue BMP-RII dysfunction and reverse SMC proliferation and vascular remodeling in PAH patients and may be useful antiproliferative agents even in those patients without BMP-RII dysfunction.

\section{Methods}

Additional and more detailed methods are provided in the supplemental materials.

Creation of mice with targeted deletion of PPAR in arterial SMCs using the Cre-loxP system. We cross-bred SM $22 \alpha$ promoter-driven Cre-transgenic mice with PPAR $\gamma$ homozygous floxed mice. Both strains were obtained from the Jackson Laboratory, and the cross resulted in SM22 $\alpha$ Cre PPAR flox/flox (SMC PPAR $\left.\gamma^{-/}\right)$mice. The offspring genotypes were determined by PCR (see Supplemental Methods). PCR conditions and primer information are available from the Jackson Laboratory. For the experiments involving PASMC isolation and subculture described below, apoE-deficient (B6.129P2-Apoetm1Unc/J) and C57BL/6 control mice were purchased from the Jackson Laboratory.

Genotyping/RT-PCR analysis. To detect the deletion of PPAR $\gamma$ exon 1 and exon 2, two primers were designed and located in exon A1 and exon 


\section{Table 1}

Invasive hemodynamic, echocardiographic, heart weight, pulmonary artery, hematocrit, wbc, and blood glucose measurements in SM22 $\alpha$ PPARy Crefloxflox (SMC PPAR $\gamma^{-1-}$ ) and littermate control mice

\begin{tabular}{|c|c|c|c|c|}
\hline & Littermate control & SMC PPAR $\gamma^{-1-}$ & $P$ & $n$ \\
\hline Body weight (g) & $22.5 \pm 0.9$ & $22.1 \pm 1.2$ & & $8-10$ \\
\hline \multicolumn{5}{|l|}{ Hemodynamics } \\
\hline $\begin{array}{l}\text { RVSP }(\mathrm{mmHg}) \\
\text { RV dP/dt max }(\mathrm{mmHg} / \mathrm{s}) \\
\text { RV } d P / d t \min (\mathrm{mmHg} / \mathrm{s}) \\
\text { Systolic BP }(\mathrm{mmHg}) \\
\text { MAP }(\mathrm{mmHg}) \\
\text { Diastolic BP }(\mathrm{mmHg})\end{array}$ & $\begin{aligned} 21.5 & \pm 0.6 \\
1,439 & \pm 144 \\
-1,228 & \pm 87 \\
105 & \pm 3.2 \\
85 & \pm 2.0 \\
74 & \pm 1.9\end{aligned}$ & $\begin{aligned} 29.0 & \pm 0.6 \\
1,718 & \pm 143 \\
-1,405 & \pm 63 \\
97 & \pm 3.1 \\
78 & \pm 3.1 \\
68 & \pm 3.1\end{aligned}$ & $P<0.001$ & $\begin{array}{l}7-8 \\
7-8 \\
7-8 \\
9-10 \\
9-10 \\
9-10\end{array}$ \\
\hline \multicolumn{5}{|l|}{ Echocardiography } \\
\hline $\begin{array}{l}\text { Heart rate (bpm) } \\
\text { Ejection fraction (\%) } \\
\text { Fractional shortening (\%) } \\
\text { Cardiac output (ml/min) } \\
\text { LVIDD (mm) } \\
\text { LVISD }(\mathrm{mm}) \\
\text { LVPWd }(\mathrm{mm}) \\
\text { IVSd (mm) }\end{array}$ & $\begin{array}{l}423 \pm 22 \\
72.7 \pm 2.2 \\
36.5 \pm 1.8 \\
35.3 \pm 2.7 \\
3.58 \pm 0.05 \\
2.26 \pm 0.09 \\
0.60 \pm 0.04 \\
0.56 \pm 0.02\end{array}$ & $\begin{array}{l}411 \pm 20 \\
76.8 \pm 1.2 \\
39.8 \pm 1.1 \\
38.7 \pm 3.6 \\
3.62 \pm 0.10 \\
2.19 \pm 0.09 \\
0.58 \pm 0.03 \\
0.55 \pm 0.02\end{array}$ & & $\begin{array}{l}9-10 \\
9-10 \\
9-10 \\
9-10 \\
9-10 \\
9-10 \\
9-10 \\
9-10\end{array}$ \\
\hline \multicolumn{5}{|l|}{ Heart weight } \\
\hline $\begin{array}{l}\text { RV/LV+S } \\
\text { RV/body weight }\left(\times 10^{3}\right)\end{array}$ & $\begin{array}{l}0.26 \pm 0.01 \\
0.88 \pm 0.05\end{array}$ & $\begin{array}{l}0.46 \pm 0.02 \\
1.33 \pm 0.05\end{array}$ & $\begin{array}{l}P<0.0001 \\
P<0.0001\end{array}$ & $\begin{array}{l}8-10 \\
8-10\end{array}$ \\
\hline \multicolumn{5}{|c|}{ Number and muscularization of pulmonary arteries } \\
\hline $\begin{array}{l}\text { No. of arteries/alveoli (\%) } \\
\text { Musc. arteries, alv. wall (\%) }\end{array}$ & $\begin{array}{l}2.2 \pm 0.2 \\
6.5 \pm 3.1\end{array}$ & $\begin{array}{r}2.3 \pm 0.2 \\
20.6 \pm 1.2\end{array}$ & $P=0.0014$ & $\begin{array}{l}5-6 \\
5-6\end{array}$ \\
\hline \multicolumn{5}{|l|}{ Blood } \\
\hline $\begin{array}{l}\text { HCT }(\%) \\
\text { wbc count }\left(\times 10^{3} \text { cells/ } \mu \mathrm{l}\right) \\
\text { Glucose }(\mathrm{mg} / \mathrm{dl})\end{array}$ & $\begin{aligned} 48.7 & \pm 0.8 \\
5.2 & \pm 0.8 \\
126.6 & \pm 6.2\end{aligned}$ & $\begin{array}{r}49.3 \pm 1.0 \\
7.4 \pm 0.4 \\
122.8 \pm 4.2\end{array}$ & $P=0.0168$ & $\begin{array}{c}8 \\
8-10 \\
9-10\end{array}$ \\
\hline
\end{tabular}

Thirteen- to 15-week-old male littermate control and SMC PPAR $\gamma^{-1-}$ mice on regular chow in normoxia. Data are shown as mean \pm SEM. Statistically significant differences $(P<0.05$; unpaired 2-tailed $t$ test) between genotypes are indicated. $d P / d t$ max., maximal rate of pressure development (systolic RV function); $d P / d t$ min., max. rate of pressure decay (diastolic RV function); MAP, mean arterial pressure; EF, ejection fraction; FS, fractional shortening; LVIDD, LV end-diastolic inner diameter; LVISD, LV end-systolic inner diameter; LVPWd, LV end-diastolic posterior wall thickness; IVSd, end-diastolic interventricular septum thickness; LV+S, LV plus septum; Alv., alveolar; Musc., muscularization; HCT, hematocrit.

4 of the Pparg1 gene for RT-PCR to recognize the full-length (700 bp) and recombined mRNA (300 bp), as previously described (49) (for primers and PCR protocol, see Supplemental Methods). Total RNA was extracted from PASMCs, aorta, and lung with TRIzOL reagent (Invitrogen). PASMCs were obtained from pulmonary arteries of SM22 $\alpha$ Cre PPAR $\gamma^{\text {flox/flox }}$ mice and littermate control mice and cultured for 10 days. Then RNA samples from the cells were reverse transcribed using the Superscript III Reverse Transcriptase kit (Invitrogen). PCR was applied to cDNA using a Taq DNA polymerase kit (Invitrogen), and transcripts were run on a $1 \%$ agarose gel.

Lentiviral shRNAi gene silencing of human BMP-RII. For long-term gene silencing of BMP-RII in HPASMCs, we constructed a pLentivirus 6 with an integrated short hairpin oligonucleotide directed against the mRNA of human BMP-RII, using an inducible H1 RNAi entry vector kit and a lentiviral RNAi expression system kit (K4920-00, K4943-00; Invitrogen) as described by the manufacturer (for details, see Supplemental Methods). Lentivirus was made and propagated in 293FT cells, and HPASMCs were transfected as described in Supplemental Methods. After 12 days of blasticidin selection, we confirmed an 85\% stable knockdown of human BMP-RII compared with shLacZi control in HPASMCs (Supplemental Figure 1) and continued with further experiments.
Cell culture. Primary murine PASMCs were isolated from 13- to 15-week-old apoE ${ }^{-/-}$and C57BL/ 6 mice, as well as SM22 $\alpha$ Cre PPAR $\gamma^{\text {flox/flox }}$ and littermate control mice, using a modified elastase/collagenase digestion protocol as previously described (50). Primary HPASMCs were purchased from Cascade Biologics. Moreover, control PASMCs were isolated from surgical resection specimens derived from a patient undergoing lobectomy or pneumonectomy for suspected lung tumor. Additional PASMCs were obtained from a patient undergoing heart-lung transplantation for FPAH and known to harbor a mutation in BMP-RII (W9X), as previously described (51). The nature of the BMP-RII mutation, cell isolation, and culture techniques are described in Supplemental Methods.

Cell proliferation assays. For determination of cell number, PASMCs were seeded at $2.5 \times 10^{4}$ cells per well of a 24 -well plate in $500 \mu \mathrm{l}$ of growth medium and allowed to adhere overnight. The medium was removed and the cells washed 3 times with PBS prior to the addition of starvation media (DMEM, $0.1 \% \mathrm{FBS}$, penicillin/streptomycin) and incubated at $37^{\circ} \mathrm{C}, 5 \% \mathrm{CO}_{2}$ for 24 hours (murine PASMCs) or 48 hours (HPASMCs) prior to PDGF-BB stimulation $(20 \mathrm{ng} / \mathrm{ml})$ for 72 hours (treatments and concentrations are given in the figure legends). The media with or without growth factors and/or inhibitors was changed every 24 hours. Cells were washed twice with PBS and trypsinized in $150 \mu \mathrm{l}$ of trypsin/EDTA for 7 minutes, followed by the addi- 
A
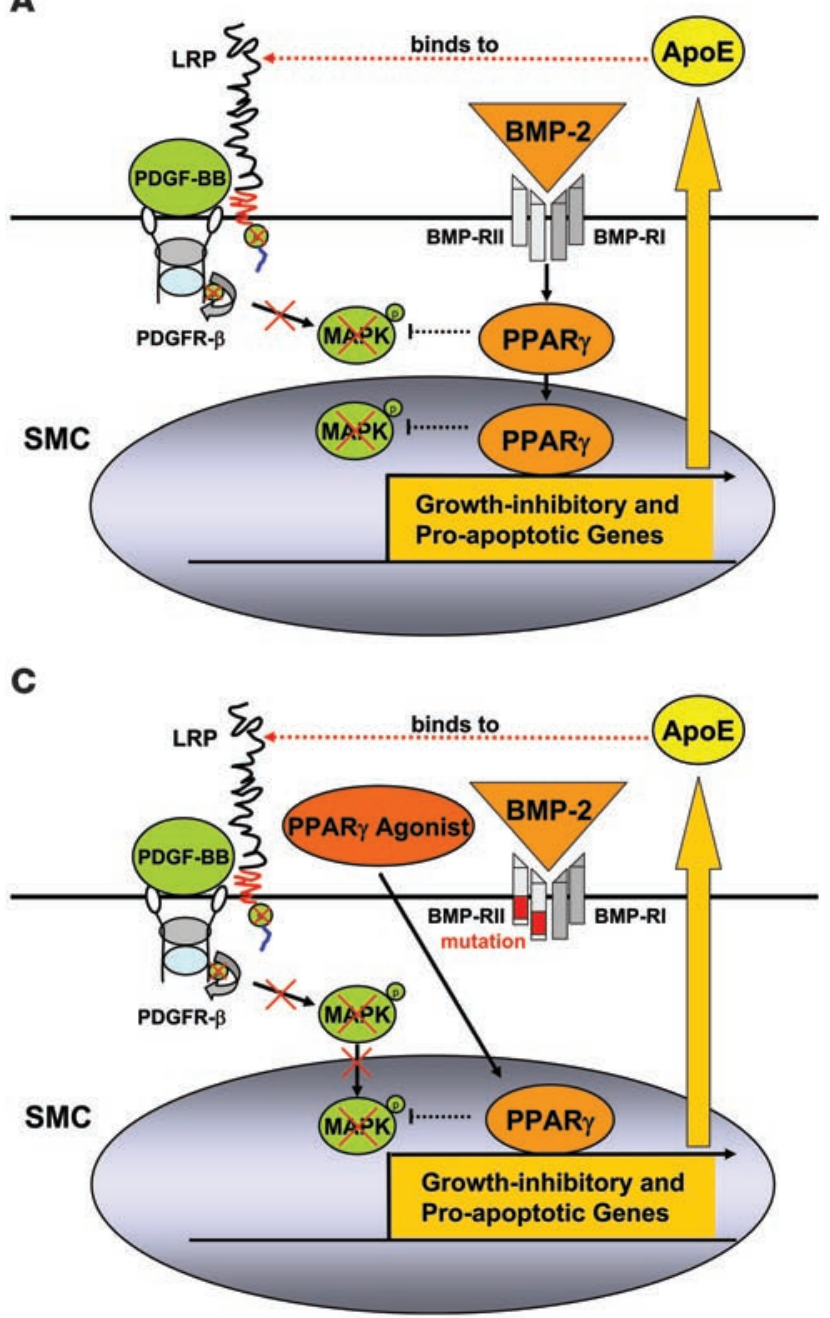

B



\section{Figure 8}

Model: A novel antiproliferative BMP-2/PPAR $\gamma / a p o E$ axis protects against PAH. This schema incorporates the findings described in our article and the literature to date as discussed. (A) BMP-2 inhibits SMC proliferation via PPAR $\gamma$ and apoE. apoE impairs PDGF-BB/MAPK signaling by binding to LDL receptor-related protein (LRP), thereby initiating endocytosis and degradation of the LRP/PDGFR- $\beta$ /PDGF-B complex. PPAR $\gamma$ induces LRP and other growth-inhibitory/proapoptotic genes in SMCs and inhibits cell-cycle and other growth-promoting genes such as telomerase, cyclin D1, and retinoblastoma protein. Moreover, PPAR $\gamma$ induces phosphatases that can directly inactivate phospho-ERK. (B) BMP-RII dysfunction promotes SMC proliferation and survival in PAH. Heightened PDGF-BB signaling leading to SMC proliferation is a key clinical feature of PAH. Deficiency of both apoE and LRP enhances mitogenic PDGF-BB/MAPK signaling. Loss-of-function mutations in the BMP-RII gene will decrease endogenous PPAR $\gamma$ activity, leading to unopposed MAPK signaling, SMC proliferation and survival, and ultimately development of PAH.TF, transcription factor. (C) PPAR $\gamma$ agonists can rescue BMP-RIl dysfunction and reverse PAH. PPAR $\gamma$ agonists such as rosiglitazone or pioglitazone might reverse SMC proliferation and vascular remodeling in PAH patients with or without BMP-RII dysfunction via induction of apoE and other growth-inhibitory/proapoptotic genes (as indicated) and through repression of growth-promoting genes (not shown).

tion of $150 \mu \mathrm{l}$ trypsin neutralizer (Cascade Biologics). The cells were then resuspended and counted in a hemacytometer (3-6 wells per condition, 4 counts per well). The biochemical MTT cell proliferation assay (ATCC) is described in Supplemental Methods. In cell proliferation studies, BMP-2 $(10 \mathrm{ng} / \mathrm{ml}$; Sigma-Aldrich), rosiglitazone (1 $\mu \mathrm{M}$; Alexis), or recombinant human apoE (1-10 $\mu \mathrm{M}$; Chemicon) were added to quiescent cells $30 \mathrm{~min}$ utes prior to mitogenic stimulation with PDGF-BB (human, $20 \mathrm{ng} / \mathrm{ml}$; R\&D Systems) for 72 hours. The PPAR $\gamma$ antagonist GW9662 ( $1 \mu \mathrm{M}$; Cayman) was added 24 hours prior to the addition of BMP-2. The media with or without growth factors and/or inhibitors was changed every 24 hours.

Protein expression and compartmental localization. Murine and human PASMCs (wild-type, shLacZi control, or shBMP-RIIi) were grown to $70 \%$ confluence and cultured in starvation media (DMEM, 0.1\% FBS, $100 \mathrm{U} / \mathrm{ml}$ penicillin, $0.1 \mathrm{mg} / \mathrm{ml}$ streptomycin; Gibco; Invitrogen) for 24 and 48 hours, respectively. PDGF-BB, BMP-2, apoE, or rosiglitazone was added to quiescent cells for 5-60 minutes and for 24 hours (treatments and concentrations are stated in the figure legends). In addition to total cell lysates, subcellular fractions (nuclear matrix, nuclear extract, cytoplasmic extract) were prepared using a modified low-salt/high-salt protocol as previously described (52). For details, see Supplemental Methods.

apoE protein secretion. Quiescent HPASMCs were cultured in T75 cell culture flasks $\left(75 \mathrm{~cm}^{2}\right)$ covered with minimal media $(1 \mathrm{ml})$ and were then stimulated with BMP-2 $(10 \mathrm{ng} / \mathrm{ml})$ or rosiglitazone $(1 \mu \mathrm{M})$ for 24 hours. The supernatant media was collected from 3 cell culture flasks per con- 
dition, pooled, and concentrated using an Amicon-4 Centriprep device (Millipore). Protein extracts were then prepared as described in Supplemental Methods, and $20 \mu \mathrm{g}$ protein per sample was loaded for SDS-PAGE immunoblotting (Invitrogen).

Western immunoblotting. Preparation of subcellular fractions (nuclear matrix, nuclear extract, cytoplasmic extract) and whole-cell lysates (protein extracts) as well as immunoblotting techniques are described in Supplemental Methods. Primary antibodies against phospho-ERK1/2, ERK 1/2, phospho-Smad1/5/8, Smad1 (all Cell Signaling Technology), PPAR $\gamma$ (Santa Cruz Biotechnology Inc.), apoE (Abcam), BMP-RII (BD Biosciences - Pharmingen), and $\alpha$-tubulin (Sigma-Aldrich) were used.

PPAR $\mathrm{DNA}$ binding assay. A multiplex transcription factor DNA binding assay (Marligen Biosciences) was performed as previously described (53). Briefly, nuclear extracts were incubated with a mixture of biotinylated DNA probes representing different transcription factor binding sites (e.g., for PPAR $\gamma, 5^{\prime}$-TGACCTTTGACCTAGAA-3'), each containing a distinct singlestranded sequence that serves as a capture tag. Following the transcription factor binding reactions, samples were incubated with proprietary reagents to digest any DNA probes not bound to transcription factors. Reactions were then incubated with a mix containing spectrally distinct bead sets, and intact biotinylated probes were captured onto corresponding bead surfaces by capture-tag and anti-tag sequence interactions. Beads were then washed using a filter plate and stained with streptavidin-PE. The fluorescent signal associated with transcription factor binding sites localized on the surface of spectrally distinct beads was measured using Luminex-100 instrumentation. Each reaction was carried out in triplicate, so that 300 different data points per sample were obtained for analysis.

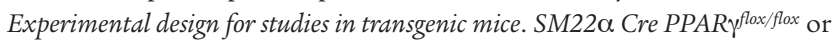
littermate control mice were maintained on regular chow with free access to drinking water. All studies were carried out in 13- to 15 -week-old mice under a protocol approved by the Animal Care Committee of Stanford University following the guidelines of the American Physiological Society.

Hemodynamic measurements. RVSP and RV $d P / d t$ measurements were performed in 15-week-old nonventilated mice under isoflurane anesthesia $\left(1.5 \%-2.5 \%, 21 \mathrm{O}_{2} / \mathrm{min}\right.$ ) by inserting a $1.4 \mathrm{~F}$ catheter (Millar Instruments) via the right jugular vein as described previously (25). Systemic blood pressure was determined in nonanesthetized, 14- to 15-week-old mice by the tail cuff method using the BP 2000 analysis system (Visitech Systems). Cardiac output and function were measured in 13- to 15-week-old mice by echocardiography under isoflurane anesthesia $\left(1 \%, 11 \mathrm{O}_{2} / \mathrm{min}\right)$ with an ultrasound machine (Vivid 7; GE Medical Systems) using a 13-MHz linear array transducer (see Supplemental Methods).

$R V H$ and $L V H$. RVH was measured as described previously (54) by the weight of the RV relative to $L V$ plus septum. LVH was measured as absolute weight of the LV plus septum relative to body weight. LV dilatation was assessed by echocardiographic M-mode measurement of the LVIDD.

Lung tissue preparation. Lungs were perfused with normal saline, fixed in $10 \%$ formalin overnight, and then embedded in paraffin for routine histology (H\&E, elastin van Gieson, Movat pentachrome), as previously described $(25,54)$. A subset of left lungs (approximately half) were injected with barium-gelatin via pulmonary artery-inserted tubing (25) to label peripheral pulmonary arteries for morphometric analysis (see Supplemental Methods).

Morphometric analysis. Barium-injected, transverse left lung step sections were stained by the elastin van Gieson method. From all mice, we took the same full section in the mid-portion of the barium-injected left lung parallel to the hilum and embedded it in the same manner. Pulmonary artery muscularization was assessed at $\times 400$ magnification by calculating the proportion of fully and partially muscularized peripheral (alveolar wall) pulmonary arteries to total peripheral pulmonary arteries in 5 random fields ( 1 field $=\times 200$ magnification). The total number of alveolar wall and duct arteries was expressed as both the ratio of number of pulmonary arteries per 100 alveoli and number of pulmonary arteries per surface area ( 5 random fields at $\times 200$ magnification). Approximately 1,000 alveoli were counted per animal. All measurements were carried out by investigators blinded to genotype and condition.

Immunohistochemistry. Paraffin-embedded sections were deparaffinized in xylene and rehydrated through graded alcohol. Antigen retrieval was performed using a heat-mediated epitope retrieval method by heating the sections in citrate buffer (10 mM sodium citrate, $0.05 \%$ Tween- $20, \mathrm{pH} 6.0$ ) for 10 minutes at $95^{\circ} \mathrm{C}$ and then allowing the sections to cool to room temperature. Sections were then incubated with primary antibodies specific for PCNA and $\alpha$-SMA (Abcam) overnight at $4^{\circ} \mathrm{C}$. Staining was then completed using the Vectastain Elite ABC Kit (Vector Laboratories) according to the manufacturer's instructions, using 3,3-diaminobenzidine as a substrate for peroxidase, and counterstained with hematoxylin.

Fasting whole-blood measurements. Tail vein puncture was performed in nonanesthetized, overnight-starved mice, followed by immediate, duplicate whole-blood glucose measurements with a glucometer (FreeStyle; Abbott), to rule out any influence of the SMC-targeted PPAR $\gamma$ knockout on glucose hemostasis. Additional blood was obtained by cardiac puncture after the hemodynamic measurements. White blood cell count and hematocrit were assessed by the Stanford Animal Facility Laboratories (see Supplemental Methods).

Statistics. Values from multiple experiments are expressed as mean \pm SEM. Statistical significance was determined using 1-way ANOVA. When only 2 groups were compared, statistical differences were assessed with the unpaired 2 -tailed $t$ test. A $P$ value of less than 0.05 was considered as significant. The number of samples or animals in each group is indicated in the figure legends.

\section{Acknowledgments}

We thank Pete Clausen (Marligen Biosciences) for help with the multiplex DNA binding assay and data analysis. This work was supported by a Postdoctoral Fellowship from the American Heart Association/Pulmonary Hypertension Association $(0425943 \mathrm{H})$ to G. Hansmann; the NIH (1-R01-HL074186-01) and the Dwight and Vera Dunlevie Endowed Professorship to M. Rabinovitch; a National Heart, Lung, and Blood Institute National Research Service Award (2-T32-HL007708-14) to J.M. Bekker; and a Predoctoral Fellowship from Boehringer Ingelheim Funds to S. Schellong. N.W. Morrell received grant funding from the British Heart Foundation.

Received for publication April 25, 2007, and accepted in revised form February 6, 2008.

Address correspondence to: Marlene Rabinovitch, Vera Moulton Wall Center for Pulmonary Vascular Disease, Stanford University School of Medicine, CCSR Building, Room 2245B, 269 Campus Drive, Stanford, California 94305-5162, USA. Phone: (650) 723-8239; Fax: (650) 723-6700; E-mail: marlener@stanford.edu.

\footnotetext{
1. Merklinger, S.L., Jones, P.L., Martinez, E.C., and Rabinovitch, M. 2005. Epidermal growth factor receptor blockade mediates smooth muscle cell apoptosis and improves survival in rats with pulmonary hypertension. Circulation. 112:423-431.
}

2. Schermuly, R.T., et al. 2005. Reversal of experimental pulmonary hypertension by PDGF inhibition. J. Clin. Invest. 115:2811-2821.

3. Lane, K.B., et al. 2000. Heterozygous germline mutations in BMPR2, encoding a TGF-beta receptor, cause familial primary pulmonary hypertension. The International PPH Consortium. Nat. Genet. 26:81-84.

4. Deng, Z., et al. 2000. Familial primary pulmonary hypertension (gene PPH1) is caused by mutations 
in the bone morphogenetic protein receptor-II gene. Am. J. Hum. Genet. 67:737-744.

5. Newman, J.H., et al. 2004. Genetic basis of pulmonary arterial hypertension: current understanding and future directions. J. Am. Coll. Cardiol. 43:33S-39S.

6. Humbert, M., et al. 2002. BMPR2 germline mutations in pulmonary hypertension associated with fenfluramine derivatives. Eur. Respir. J. 20:518-523.

7. Roberts, K.E., et al. 2004. BMPR2 mutations in pulmonary arterial hypertension with congenital heart disease. Eur. Respir. J. 24:371-374.

8. Atkinson, C., et al. 2002. Primary pulmonary hypertension is associated with reduced pulmonary vascular expression of type II bone morphogenetic protein receptor. Circulation. 105:1672-1678.

9. Galetto, R., et al. 2001. Identification of a peroxisome-proliferator-activated-receptor response element in the apolipoprotein E gene control region. Biochem. J. 357:521-527.

10. Ameshima, S., et al. 2003. Peroxisome proliferator-activated receptor gamma (PPARgamma) expression is decreased in pulmonary hypertension and affects endothelial cell growth. Circ. Res. 92:1162-1169.

11. Geraci, M.W., et al. 2001. Gene expression patterns in the lungs of patients with primary pulmonary hypertension: a gene microarray analysis. Circ. Res. 88:555-562.

12. Marx, N.N., Duez, H.H., Fruchart, J.C., and Staels, B.B. 2004. Peroxisome proliferator-activated receptors and atherogenesis: regulators of gene expression in vascular cells. Circ. Res. 94:1168-1178.

13. Gilde, A.J., Fruchart, J.C., and Staels, B. 2006. Peroxisome proliferator-activated receptors at the crossroads of obesity, diabetes, and cardiovascular disease. J. Am. Coll. Cardiol. 48:A24-A32.

14. Benkirane, K., Amiri, F., Diep, Q.N., El Mabrouk, M., and Schiffrin, E.L. 2006. PPAR-gamma inhibits ANG II-induced cell growth via SHIP2 and 4E-BP1. Am. J. Physiol. Heart Circ. Physiol. 290:H390-H397.

15. Wakino, S., et al. 2001. Peroxisome proliferatoractivated receptor gamma ligands inhibit mitogenic induction of p21(Cip1) by modulating the protein kinase Cdelta pathway in vascular smooth muscle cells. J. Biol. Chem. 276:47650-47657.

16. Akiyama, T.E., et al. 2002. Conditional disruption of the peroxisome proliferator-activated receptor gamma gene in mice results in lowered expression of ABCA1, ABCG1, and apoE in macrophages and reduced cholesterol efflux. Mol. Cell. Biol. 22:2607-2619.

17. Yue, L., Rasouli, N., Ranganathan, G., Kern, P.A., and Mazzone, T. 2004. Divergent effects of peroxisome proliferator-activated receptor gamma agonists and tumor necrosis factor alpha on adipocyte ApoE expression. J. Biol. Chem. 279:47626-47632.

18. Zeleny, M., Swertfeger, D.K., Weisgraber, K.H., and Hui, D.Y. 2002. Distinct apolipoprotein E isoform preference for inhibition of smooth muscle cell migration and proliferation. Biochemistry. 41:11820-11823.

19. Ishigami, M., Swertfeger, D.K., Granholm, N.A., and Hui, D.Y. 1998. Apolipoprotein E inhibits platelet-derived growth factor-induced vascular smooth muscle cell migration and proliferation by suppressing signal transduction and preventing cell entry to G1 phase. J. Biol. Chem. 273:20156-20161.

20. Boucher, P., Gotthardt, M., Li, W.P., Anderson, R.G., and Herz, J. 2003. LRP: role in vascular wall integrity and protection from atherosclerosis. Science. 300:329-332.

21. Newton, C.S., et al. 2005. Platelet-derived growth factor receptor-beta (PDGFR-beta) activation promotes its association with the low density lipopro- tein receptor-related protein (LRP). Evidence for coreceptor function. J. Biol. Chem. 280:27872-27878.

22. Lassila, M., et al. 2004. Imatinib attenuates diabetes-associated atherosclerosis. Arterioscler. Thromb. Vasc. Biol. 24:935-942.

23. Humbert, M., et al. 1998. Platelet-derived growth factor expression in primary pulmonary hypertension: comparison of HIV seropositive and HIV seronegative patients. Eur. Respir. J. 11:554-559.

24. Ghofrani, H.A., Seeger, W., and Grimminger, F. 2005. Imatinib for the treatment of pulmonary arterial hypertension. N. Engl. J. Med. 353:1412-1413.

25. Hansmann, G., et al. 2007. Pulmonary arterial hypertension is linked to insulin resistance and reversed by peroxisome proliferator-activated receptor-gamma activation. Circulation. 115:1275-1284.

26. Ghosh, S.S., et al. 2003. PPARgamma ligand attenuates PDGF-induced mesangial cell proliferation: role of MAP kinase. Kidney Int. 64:52-62.

27. Goetze, S., et al. 2001. Peroxisome proliferator-activated receptor-gamma ligands inhibit nuclear but not cytosolic extracellular signal-regulated kinase/ mitogen-activated protein kinase-regulated steps in vascular smooth muscle cell migration. J. Cardiovasc. Pharmacol. 38:909-921.

28. Hu, E., Kim, J.B., Sarraf, P., and Spiegelman, B.M. 1996. Inhibition of adipogenesis through MAP kinase-mediated phosphorylation of PPARgamma. Science. 274:2100-2103.

29. Ishihara, K., Tsutsumi, K., Kawane, S., Nakajima, M., and Kasaoka, T. 2003. The receptor for advanced glycation end-products (RAGE) directly binds to ERK by a D-domain-like docking site. FEBS Lett. 550:107-113.

30. Sarjeant, J.M., et al. 2003. Apolipoprotein D inhibits platelet-derived growth factor-BB-induced vascular smooth muscle cell proliferated by preventing translocation of phosphorylated extracellular signal regulated kinase $1 / 2$ to the nucleus. Arterioscler. Thromb. Vasc. Biol. 23:2172-2177.

31. Burgermeister, E., et al. 2007. Interaction with MEK causes nuclear export and downregulation of peroxisome proliferator-activated receptor gamma. Mol. Cell. Biol. 27:803-817.

32. Floyd, Z.E., and Stephens, J.M. 2002. Interferongamma-mediated activation and ubiquitin-proteasome-dependent degradation of PPARgamma in adipocytes. J. Biol. Chem. 277:4062-4068.

33. Ishigami, M., et al. 2000. Apolipoprotein E inhibition of vascular smooth muscle cell proliferation but not the inhibition of migration is mediated through activation of inducible nitric oxide synthase. Arterioscler. Thromb. Vasc. Biol. 20:1020-1026.

34. Arita, Y., et al. 2002. Adipocyte-derived plasma protein adiponectin acts as a platelet-derived growth factor-BB-binding protein and regulates growth factor-induced common postreceptor signal in vascular smooth muscle cell. Circulation. 105:2893-2898.

35. Zhang, J., Fu, M., Zhao, L., and Chen, Y.E. 2002. 15-Deoxy-prostaglandin J(2) inhibits PDGF-A and -B chain expression in human vascular endothelial cells independent of PPAR gamma. Biochem. Biophys. Res. Commun. 298:128-132.

36. Gauthier, A., Vassiliou, G., Benoist, F., and McPherson, R. 2003. Adipocyte low density lipoprotein receptor-related protein gene expression and function is regulated by peroxisome proliferator-activated receptor gamma. J. Biol. Chem. 278:11945-11953.

37. Martin-Nizard, F., et al. 2002. Peroxisome proliferator-activated receptor activators inhibit oxidized low-density lipoprotein-induced endothelin-1 secretion in endothelial cells. J. Cardiovasc. Pharmacol. 40:822-831.

38. Wakino, S., et al. 2005. Pioglitazone lowers sys- temic asymmetric dimethylarginine by inducing dimethylarginine dimethylaminohydrolase in rats. Hypertens. Res. 28:255-262.

39. Kielstein, J.T., et al. 2005. Asymmetrical dimethylarginine in idiopathic pulmonary arterial hypertension. Arterioscler. Thromb. Vasc. Biol. 25:1414-1418.

40. Wakino, S., et al. 2000. Peroxisome proliferatoractivated receptor gamma ligands inhibit retinoblastoma phosphorylation and G1--> S transition in vascular smooth muscle cells. J. Biol. Chem. 275:22435-22441.

41. Ogawa, D., et al. 2006. Activation of peroxisome proliferator-activated receptor gamma suppresses telomerase activity in vascular smooth muscle cells. Circ. Res. 98:e50-e59.

42. Vantler, M., Caglayan, E., Zimmermann, W.H., Baumer, A.T., and Rosenkranz, S. 2005. Systematic evaluation of anti-apoptotic growth factor signaling in vascular smooth muscle cells. Only phosphatidylinositol 3'-kinase is important. J. Biol. Chem. 280:14168-14176.

43. Bruemmer, D., et al. 2003. Regulation of the growth arrest and DNA damage-inducible gene 45 (GADD45) by peroxisome proliferator-activated receptor gamma in vascular smooth muscle cells. Circ. Res. 93:e38-e47.

44. Worley, J.R., et al. 2003. Metalloproteinase expression in PMA-stimulated THP-1 cells. Effects of peroxisome proliferator-activated receptor-gamma (PPAR gamma) agonists and 9-cis-retinoic acid. J. Biol. Chem. 278:51340-51346.

45. Nagase, H., Enghild, J.J., Suzuki, K., and Salvesen, G. 1990. Stepwise activation mechanisms of the precursor of matrix metalloproteinase 3 (stromelysin) by proteinases and (4-aminophenyl)mercuric acetate. Biochemistry. 29:5783-5789.

46. Cowan, K.N., et al. 2000. Complete reversal of fatal pulmonary hypertension in rats by a serine elastase inhibitor. Nat. Med. 6:698-702

47. Nakaoka, T., et al. 1997. Inhibition of rat vascular smooth muscle proliferation in vitro and in vivo by bone morphogenetic protein-2. J. Clin. Invest. 100:2824-2832.

48. Risner, M.E., et al. 2006. Efficacy of rosiglitazone in a genetically defined population with mild-tomoderate Alzheimer's disease. Pharmacogenomics J. 6:246-254.

49. Hevener, A.L., et al. 2003. Muscle-specific Pparg deletion causes insulin resistance. Nat. Med. 9:1491-1497.

50. Fouty, B.W., et al. 2001. p27(Kip1) is important in modulating pulmonary artery smooth muscle cell proliferation. Am. J. Respir. Cell Mol. Biol. 25:652-658.

51. Yang, X., Lee, P.J., Long, L., Trembath, R.C., and Morrell, N.W. 2007. BMP4 induces HO-1 via a Smad-independent, p38MAPK-dependent pathway in pulmonary artery myocytes. Am. J. Respir. Cell Mol. Biol. 37:598-605.

52. Mitani, Y., Zaidi, S.H., Dufourcq, P., Thompson, K., and Rabinovitch, M. 2000. Nitric oxide reduces vascular smooth muscle cell elastase activity through cGMP-mediated suppression of ERK phosphorylation and AML1B nuclear partitioning. FASEB J. 14:805-814.

53. Shurin, G.V., et al. 2005. Loss of new chemokine CXCL14 in tumor tissue is associated with low infiltration by dendritic cells (DC), while restoration of human CXCL14 expression in tumor cells causes attraction of DC both in vitro and in vivo. J. Immunol. 174:5490-5498.

54. Zaidi, S.H., You, X.M., Ciura, S., Husain, M., and Rabinovitch, M. 2002. Overexpression of the serine elastase inhibitor elafin protects transgenic mice from hypoxic pulmonary hypertension. Circulation. 105:516-521. 